\title{
On practical teaching system for cultivating foreign language skills based on the job requirement
}

\author{
Huanhuan $\operatorname{Ren}^{1, a}$, Chi Ma ${ }^{2, b}$ \\ ${ }^{1}$ Teaching and Research Institute of Foreign Languages, Bohai University, Jinzhou, 121013, China \\ ${ }^{2}$ Jinzhou Institute of Forestry Research, Jinzhou Forestry Bureau, Jinzhou, 121013, China \\ a email: renhuanhuan2014@163.com, bemail: machi2014@tom.com
}

Keywords: Practical Teaching System; Foreign Language Skills; Job Requirement

\begin{abstract}
It's true that learning a foreign language can benefit students, however it's never an easy job, or even a lot harder if learners fall into wrong teaching pedagogy. With regard to the job requirement, it's suggested that different levels of foreign language skills and various specialties of foreign language skills be considered whilst establishing practical foreign language teaching system. Furthermore, a balanced approach, which including multi-module approach, multi-layer approach, multi-grade approach and multi-stage approach, are proposed in the process of establish teaching system to maintain and develop proficiency in foreign language and cultivate all-around language skills of language learners.
\end{abstract}

\section{Introduction}

Without question, the issue investigated most often in research pertinent to foreign language education is a set of language skills developed by learners. Foreign language learners are required to be linguistically and culturally equipped to communicate successfully in a pluralistic society or even world. It's true that learning a foreign language can benefit students, however it's never an easy job, or even a lot harder if learners fall into wrong teaching pedagogy. This paper is an attempt to look at practical teaching system for cultivating foreign language skills based on the job requirement. It includes literature review of foreign language learning, the implication of job requirement for cultivating foreign language skills, and practical teaching system with regard to the job requirement. Whist establishing practical teaching system based on the job requirement, a balanced approach is adopted to maintain and develop proficiency in foreign language and cultivate all-around language skills of language learners.

\section{Literature Reviews on Foreign Language Learning}

Nature of language acquisition. Language and communication are at the heart of the human experience. Nobody can live without using any language. According to Eric Lenneberg, language is a natural phenomenon, namely an aspect of one's biological nature, to be studied in the same manner as, for instance, his anatomy[1]. Human language is also considered by many modern linguistics as a natural object. Language can be vocalized as in speech, or manual as in sign, and the human language capacity is represented in the brain[2]. Language acquisition is one of the quintessential human traits[3]. Human beings have the species-specific ability to acquire a language, as non-humans do not communicate by using language. The capacity to successfully use language requires one to acquire a range of tools including syntax, phonetics, and an extensive vocabulary[4]. Specifically, language acquisition involving humans' capacity to perceive and comprehend language, as well as to produce and use words to communicate[5]. Through the use of language, speakers are concerned not with the form of their utterances but with the messages they are conveying and understanding. It requires meaningful interaction in the natural communication. In a word, door opens as language is created and utilized by human beings.

Needs for FL learning. There is now a growing appreciation of the role that multilingual individuals can play in an increasingly diverse society, and there are more people who need to learn 
a foreign language (FL) in order to improve their professional and academic lives. Of course, the benefits of learning another language are fairly clear and far more than what we mentioned. As concluded by scholars in Duke University, the five C's of foreign language education can encompass all reasons and benefits of learning a foreign language, which are communication, cultures, connections, comparisons, and communities.[6] And when coming to specific foreign language people learn, English is the first choice of foreign language in most other countries of the world. It has become increasingly necessary for non-English speakers to be able to communicate in the English language, as English is an important part of globalization which enhances international communication. Hence, EFL (English as foreign language) learning presents young people today with more things than before, and there is a greater understanding of various opportunities and possibilities that may accrue from EFL learning.

Foreign language skills. Good communication in foreign language becomes crucial in today's world owing to the impact of globalization. However, many of foreign language learners experience one problem that they studied a foreign language in college but never used it again. Explanations for this phenomenon is twofold. On one hand, foreign language learners should actively seek for more chances of utilizing foreign language regardless of their farewell to pedagogical scenarios. On the other, efficient and effective communities in life and in workplace are enabled with strong foreign language skills, including reading, writing, listening, speaking, or even translating and interpreting. The fact is that students remain orally incompetent despite being structurally knowledgeable in the foreign language learning setting. They can read and write, but they can't communicate orally with foreign people. For global competitors, foreign language learners are expected to possess the ability to communicate on a wider, quicker and clearer basis. These expertise and experience can boost self-confidence of foreign language learners. Thereby cultivation of overall foreign language skills, especially communicative skills, is indispensable and critical for any foreign language teaching system.

\section{The Implications of Cultivating Foreign Language Skills Based on the Job Requirement}

The impact of the job requirement on cultivating foreign language skills should not be neglected, but rather be highly considered. The foreign language skills of learners are anticipated to be cultivated with regard to the job requirement in workplace. Specifically, the implications of cultivating foreign language skills are reflected from two aspects, namely cultivation of different levels of foreign language skills and cultivation of different specialties of foreign language skills.

Different levels of foreign language skills. Although foreign language learning presents young people today with opportunities to communicate with non-English speaking peers on equal terms, we cannot therefore expect foreign language learners to achieve the same level of foreign language skills. After all, not all learners are anticipated to serve in a job post where higher level of foreign language skills are required. For students in hopes of finding jobs in the international marketplace, the level of foreign language proficiency is required to be much higher so that they can perform better in the targeted job, while for those whose future jobs are by no means related to the field of foreign language, they are not expected to have good command of foreign language, and perhaps the only thing for them regarding to foreign language is to fulfill a graduation requirement.

In summary, English has become the most important language around the world, but not every body is anticipated to learn it well. If learning situation becomes intolerable and students find themselves totally unable to master even the most elementary aspects of a foreign language, then alternatives may need to be considered.

Various specialities of foreign language skills. What works for one may not work for another. One person succeeds in one aspect of language learning dos not mean every one will. Foreign language learners have different specialties in language learning. Some foreign language students perform well in one part of language learning (e.g. memorizing vocabulary), but did not perform well in other parts (e.g. grammar). Just as Schwartz observed in his research, some people are savvy about dealing with sounds and sound-symbol learning, while some have problems with this auditory ability. [7] Still some are interested in the intellectual challenge and cognitive benefits of foreign 
language learning, and some may seek greater understanding of other people and other cultures. It's agreed that our capacities and interests of learning language is different. Therefore teachers should forego a certain extent of control in foreign language learning and establish an customized environment for language learners to grow and develop in supportive pedagogical setting.

In sum, different jobs have different job requirements, and not all jobs require their job candidates to be well equipped to use language in free, appropriate, and infinite ways, and language learners are encouraged to find their way in foreign language learning by choosing courses which are most suitable to their own specialties .

\section{Teaching System for Cultivating Foreign Language Skills Based on the Job Requirement}

A balanced approach is adopted to establish teaching system toward cultivating foreign language skills based on the job requirement. The teaching system proposed in this paper features multi-module, multi-layer, multi-grade and multi-stage teaching approaches. The delicate integration of the four approaches will give rise to high level of foreign language skills of language learners.

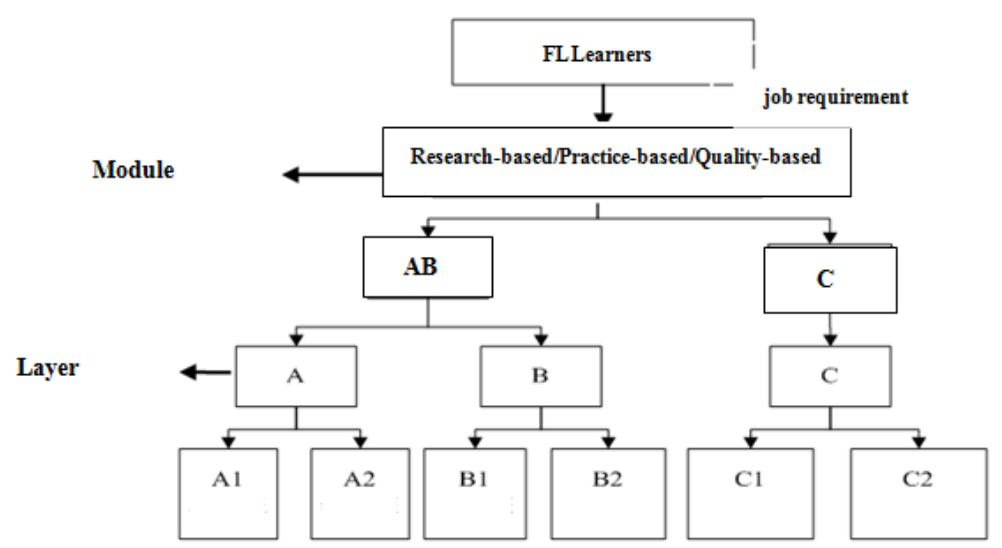

Fig.1. A balanced approach to practical teaching system

Multi-module teaching system for cultivating foreign language skills. There is a need for multi-module teaching system for cultivating foreign language skills based on the job requirement. Here is a question concerning with whether language teachers should present all foreign language learners with a common modern language curriculum. The purposes of foreign languages are as diverse as the students who study them. If langue teachers are irrespective of any additional support needs which learners may have, it's equal to deprive students of what may prove to be a worthwhile and satisfactory learning experience. With regard to the job requirement, three kinds of modules are incorporated into foreign language teaching system, namely, research-based module, practice-based module and quality-based module, as shown in Fig.1. The first module, research-based module, is designed for further academic ambition, involving more specialized English leaning in a bilingual way; practice-based module is supportive for practical language skills in workplace, especially all-around communicative skills; quality-based module concerns with the increase in culture awareness, humanistic qualities and emotion accomplishment of language learners. All in all, those three modules are open to language learners, and foreign language learners is thought to be helped a great deal by choosing the most appropriate language teaching module for them.

Multi-layer teaching system for cultivating foreign language skills. All language learners are not the same, and the abilities of learners to learn foreign language are not the same too. We cannot expect foreign language learners to absorb information at the same pace as their peers. Numerous explanations have been proposed and debated concerning why some students do not perform well in foreign language courses, and appropriate teaching will undoubtedly make an enormous difference. It's suggested that multi-layer teaching system be deployed for cultivating foreign language skills based on the job requirement. Language students are divided into three layers, namely layer A, layer $\mathrm{B}$ and layer $\mathrm{C}$, based on foreign language proficiencies of learners at the very beginning of each 
semester, as shown in Fig.1. Students in these three layers learn the same textbook, but only learn at different pace. Language classes within layer A are partaken by language students with excellent foreign language proficiency who learn at a fast pace; language classes within layer B are made up of students with medium level of foreign language skills who learn at a moderate pace; language classes within layer $\mathrm{C}$ are chosen by students with weak foreign language capacity who learn at a low space. In a word, learning foreign language is not a challenge taken up by every learner if language learners can make full advantage of multi-layer language teaching system.

Multi-grade teaching system for cultivating foreign language skills. Students at different grade are anticipated to choose different learning textbook. The textbooks are designed in a series of grades with various focuses, from reading and understanding, dealing with unfamiliar words, enhancing intercultural awareness, to developing critical thinking. For critical thinking, learners are encouraged to look beyond the passages and consider the broader implications of what they have read or listened to. The idea behind multi-grade teaching system for cultivating foreign language skills based on the job requirement, is to learn a language step by step. Learning materials suitable to different learning levels are provided to learners. Totally four grades are made out for foreign language learners in college, namely grade one, grade two, grade three and grade four, taking all skills of foreign language (e.g. reading, writing, listening and speaking) into consideration. Courses of grade one are selected by students in the first term of the first year; courses of grade two are given to students in the second term of the first year; courses of grade three are open to students in the first term of the second year; courses of grade four are provided for students in the second term of the second year. In brief, the benefits of cultivating foreign language skills may accrue from multi-grade teaching system if learners make learning experience worthwhile and enjoyable one in multi-grade teaching system.

Multi-stage teaching system for cultivating foreign language skills. Teaching system stuck in stable and change-resistant situation is never an efficient one. All things are subject to change, and learners are no exception. Students with lower foreign language capacity don't mean that they will never go to higher level of foreign language proficiency. It's suggested that multi-stage teaching system be applied into universities and colleges for cultivating foreign language skills on the job requirement. It's a teaching system with a high degree of flexibility and openness. Students are not fixed by a certain language course all way along, and they can move to other courses based on the language assessment conducted every half year. In other words, every half of an academic year is just a stage when learners can make a choice on language courses. Slowing the pace may give language learners in courses within layer $\mathrm{C}$ more time to process information during the initial stages of learning. Quite possibly, the more years devoted to learning a language, the greater the proficiency achieved. Those who have achieved the learning proficiency or have reached a reasonable standard we hoped, can choose courses within layer B or above to further their language learning. Likewise, students who find a hard time in course within one module can choose courses in other modules for a change. Otherwise, students may breakdown not just in learning but also in motivation and self-esteem. In all, learners are expected to feel accepted and involved in an suitable and enjoyable learning setting when multi-stage teaching system are adopted for cultivating foreign language skills in foreign language learning process.

\section{Summary}

It is clear to see from the findings that the impact of job requirement on teaching system for cultivating foreign language skills is profound. With regard to the job requirement, different levels of foreign language skills and various specialties of foreign language skills should be taken into consideration whilst establishing practical foreign language teaching system. Furthermore, a balanced approach should be adopted in the process of establishing practical teaching system, including multi-module approach, multi-layer approach, multi-grade approach and multi-stage approach. Despite the fact that it is still at an exploratory stage, it's argued that this foreign language teaching system is conducive to enhancing all-around foreign language skills of language learners with plenty of potential for further development. 


\section{Acknowledgement}

This work is part of the project of On Cultivating and Developing Liaoning Scientific Foreign Language Talents with View to Bourdieu' Theory, the project of On Establishing Generative Mechanism of EFL Autonomous Learning Behaviors and Strengthening Development of Learning Field in Ubiquitous Learning Space, and the project of On Constructing Mechanism and Strategies for College English Autonomous Learning Abilities via Mobile Multimedia. This research was supported by the fund of Liaoning Planning of Philosophy and Social Science (Project No. L16CYY001), the fund of Liaoning Provincial Federation Social Science Circles (Project No. 2017lslktyb-019), and the fund of the Thirteenth Five-Year Plan of Education Sciences of Liaoning Province (Project No. JG16DB013).

\section{References}

[1] Eric H. L., Biological Foundations of Language.Bennett Books Ltd,1967.

[2] https://en.wikipedia.org/wiki/Language_acquisition

[3] "PubMed Celebrates its 10th Anniversary". Technical Bulletin. United States National Library of Medicine. 2006-10-05. Retrieved 2011-03-22.

[4] https://en.wikipedia.org/wiki/Language_acquisition

[5] https://en.wikipedia.org/wiki/Language_acquisition

[6] https://assessment.trinity.duke.edu/documents/StandardsforForeignLanguageLearning.pdf

[7]Schwartz, R. Learning disabilities and foreign language learning. Retrieved September 17, 2007 from LD Online at http://www.ldonline.org/article/6055. 